\title{
65 The immunology of overuse syndrome
}

It is usually inexperienced, overly ambitious athletes who are affected by overuse syndrome. Initially, the afflicted person notices their rapidly waning physical performance capability. Then, health-related impairments develop, the extent of which may be considerable.

Like every physical overload, overtraining syndrome (OTS) starts with an inflammation reaction mediated by the interleukins $\mathbf{1}$ and $\mathbf{6}$ as well as tumor necrosis factor $\boldsymbol{\alpha}$ to repair microruptures in muscles and connective tissue. These messenger substances are also produced by the muscles as myokines ( $\triangleright$ Chapter 47 ).
In the case of chronic physical overloading, the actual local process gradually turns into a systemic one. The interleukin 1 circulating in the limbic system triggers fatigue and occasional depression. The two interleukins mentioned above cause hormone reductions in the gonads, resulting in irregular menstrual cycles and loss of libido. Moreover, they stimulate the adrenal glands to increase cortisol production. Cortisol promotes the formation of glucose from glutamine. this amino acid is then lacking for special functions in the immune system. In addition, cortisol inhibits interleukin $\mathbf{2}$ and thereby negatively impacts the cellular immune defenses.

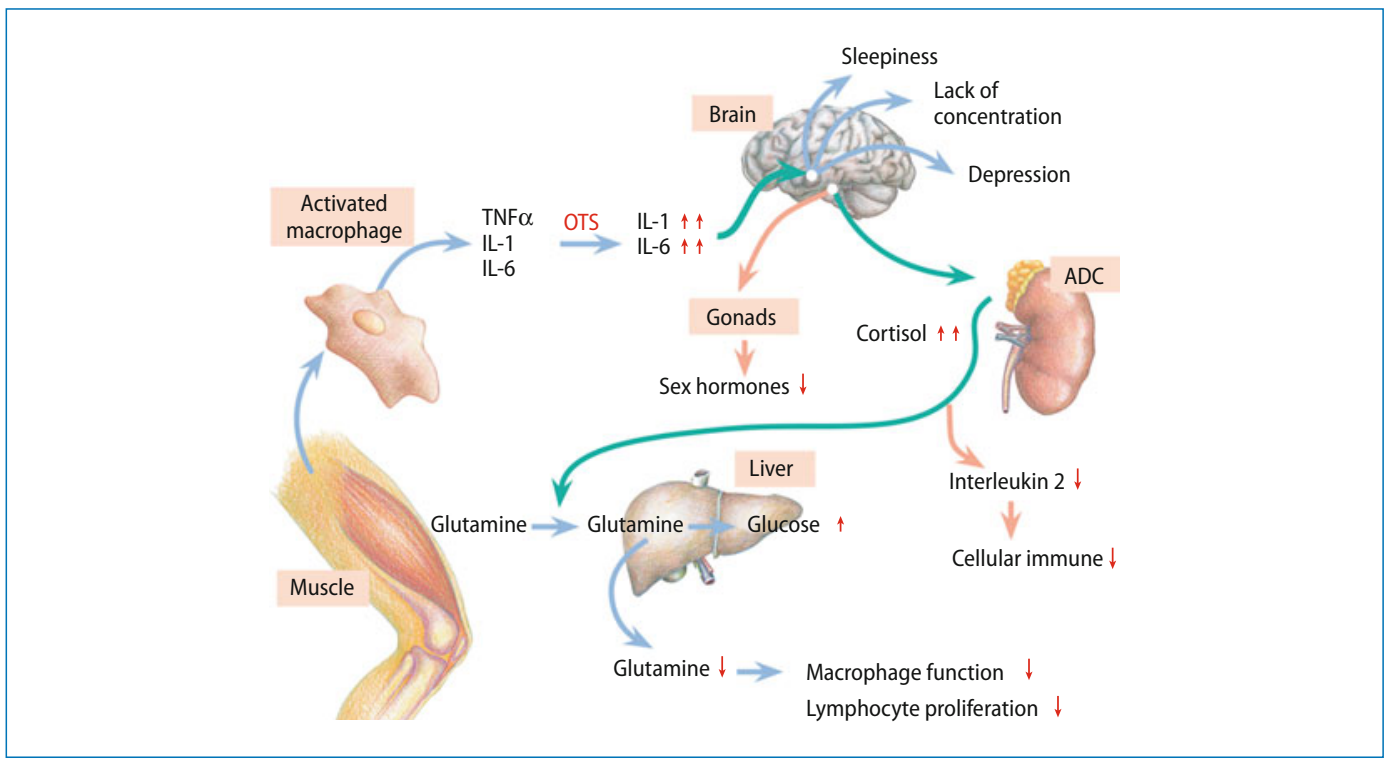

- Fig. 65.1 Biochemical processes during overloading: $\uparrow$ increase, $\downarrow$ reduction, OTS Over Training Syndrome, ADC adrenal cortex 